\title{
Status of Renewable ENERGY IN EUROPE, U.S. AND JAPAN
}

\section{Pathom Attaviriyanupap}

Association of Thai Professionals in Japan

E-mail: pathom@flute.ocn.ne.jp

\section{ABSTRACT}

As a countermeasure to reduce $\mathrm{CO}_{2}$ emission and secure energy supply, usage of renewable energy sources such as wind and solar energy is supported by government bodies around the world. Although renewable energy contributes to $\mathrm{CO}_{2}$ reduction and energy security, there are concerns about the potential negative impacts on power system operation because existing electric power system are not ready for a significant deployment of renewable energy sources, particularly wind and photovoltaic power generation, the outputs of which vary with weather conditions. In this paper, the author summarizes the current status and projection of wind and photovoltaic power generation in Europe, U.S. and Japan. Possible impacts of a large-scale penetration of these intermittent energy sources on power system operation are also addressed.

\section{KEYWORDS}

photovoltaic, power system, renewable energy source, solar energy, wind power generation 


\section{Introduction}

The demand for electricity tends to increase every year in proportion to economic and social development and lifestyle. Since 1990, world electricity consumption grew by an average of $1.9 \%$ per year and reached 17110 billion $\mathrm{kWh}$ in 2007. The U.S. Energy Information Administration (EIA) has estimated that world electricity consumption will increase and is likely to double by 2030 [1]. On the other hand, there is currently worldwide concern in environmental issues such as global warming. As a principal cause of global warming, $\mathrm{CO}_{2}$ emission is a major problem in the electric power industry.

To reduce $\mathrm{CO}_{2}$ emission and secure a sustainable energy supply, the usage of renewable energy resources (RES), such as wind and solar energy has been supported by government bodies around the world. For example, Japan and many states in U.S. apply Renewable Portfolio Standard (RPS) that obliges electricity retailers to use a certain amount of electricity from RES, according to the amount of retailing electricity. Germany and several European countries employ Feed-in-Tariff (FIT) scheme, which guarantees grid access and pay a fixed price for electricity generated from RES for a certain period of time.f

As shown in Figure 1, the world's total installed capacity of wind power generation reached $120 \mathrm{GW}$ at the end of 2008 , with annual growth rate of $22 \%$. Three regions, Europe, North America and Asia, are driving global wind development. In Europe, wind is the fastest growing power technology and plays an important role in the European energy mix. In North America, the massive growth in the U.S. wind market increased the country's total installed capacity to $25 \mathrm{GW}$, passing Germany to become the number one market in wind power as shown in Figure 2. The growth in Asian market has been driven by China, which has doubled its installed capacity annually in the recent years. According to the Global Wind Energy Council (GWEC), global wind generating capacity could reach 332 GW by 2013 [2].

On the other hand, the world's total installed capacity of photovoltaic (PV) power generation is approximately $15 \mathrm{GW}$ at the end of 2008 as shown in Figure 3. Europe contributes more than $65 \%$ of the global market. According to European Photovoltaic Industry Association (EPIA), the global PV industry is expected to grow at an average annual growth rate of $20 \%$ to $30 \%$ and reach $22 \mathrm{GW}$ by 2013 [3].

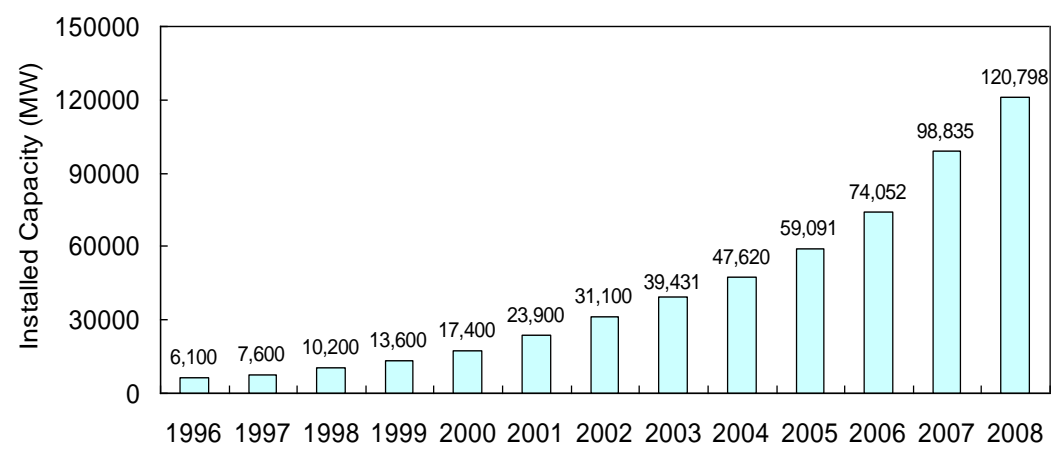

Figure 1

Global Cumulative

Installed Capacity of

Wind Power

Generation

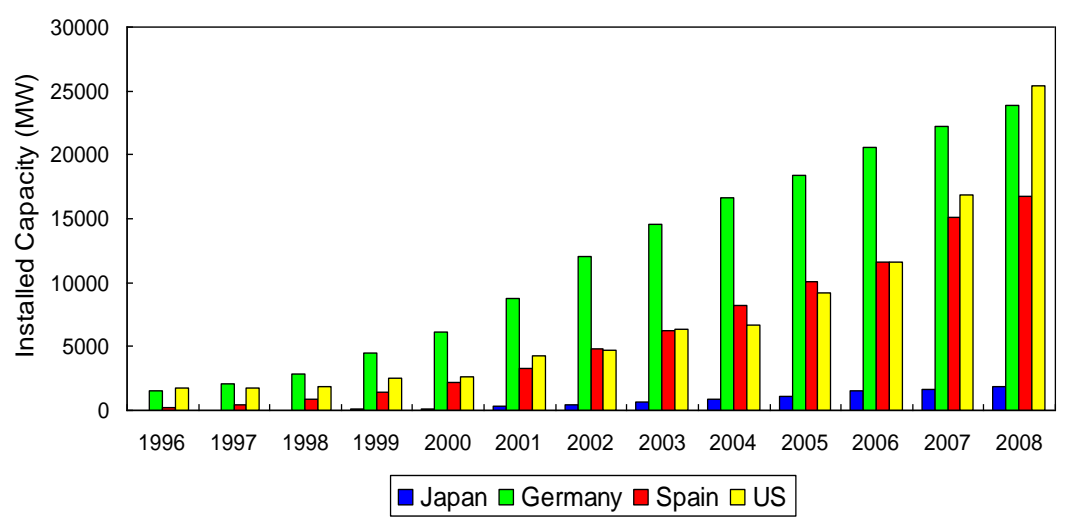

Figure 2

Installed Capacity

of Wind Power

Generation in

Selected Countries 
Figure 3

Global Cumulative Installed Capacity of Photovoltaic Power Generation

\section{Figure 4}

Installed Capacity of Photovoltaic Power Generation in Selected Countries
Source: IEA Photovoltaic Power System Programme and European Photovoltaic Industry Association
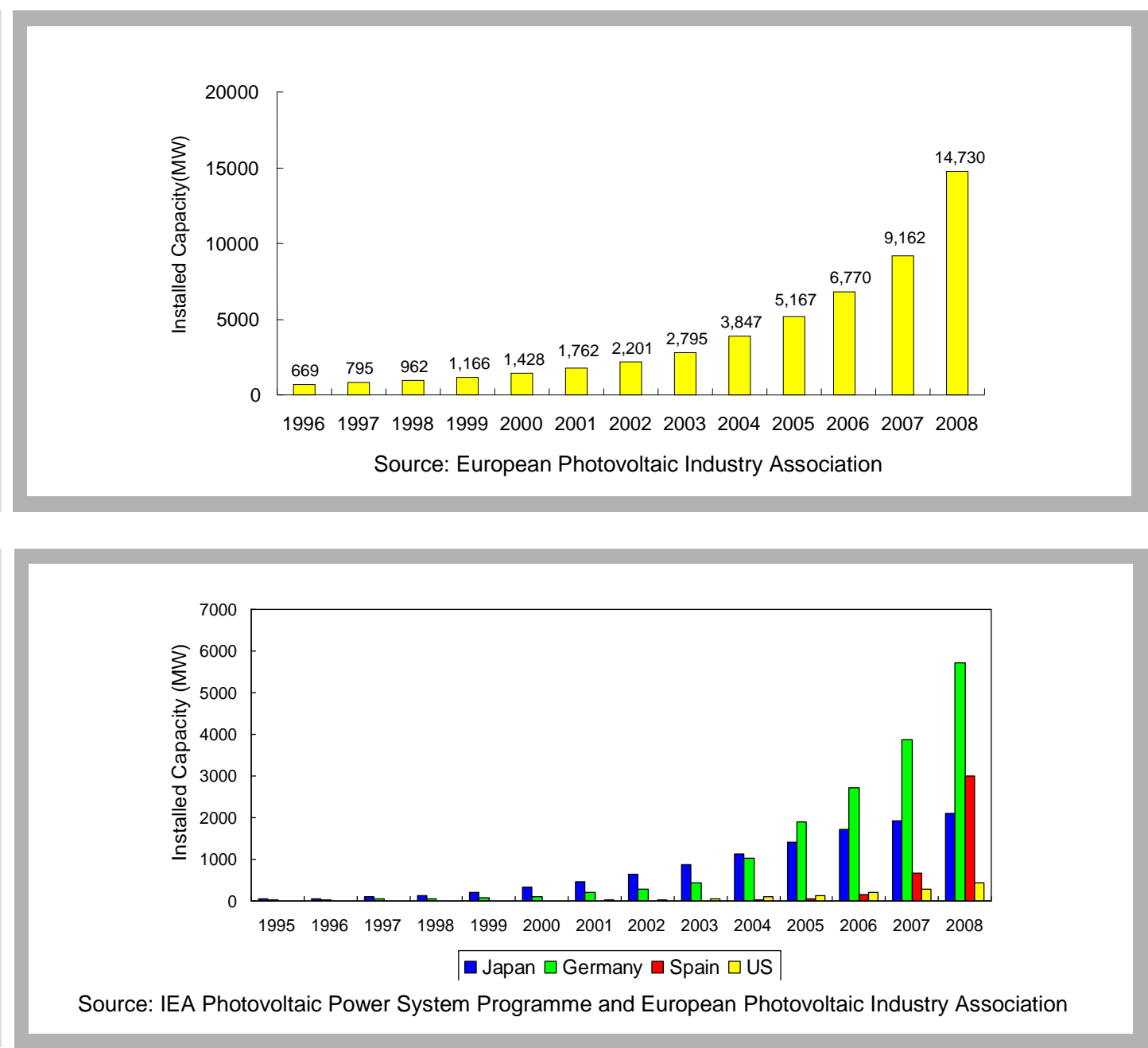

Although RES contributes to $\mathrm{CO}_{2}$ reduction and energy security, there are concerns about the potential negative impacts on power system operation because the existing electric power systems are not ready for a significant deployment of RES, particularly intermittent energy sources such as wind and solar energy. For example, it has been pointed out that the current Japanese power system might accept the interconnection of up to $5 \mathrm{GW}$ and $10 \mathrm{GW}$ of wind and PV power generation, respectively. Higher penetration requires a major renovation of power system infrastructure and method of operation [4].

This paper summarizes the current status and projection of wind and PV power generation in the world's leading countries in renewable energy production. The possible impacts of large penetration of wind and PV power generation on power system operation are also addressed.

\section{Status of Renewable Energy in EU}

\subsection{Policy Background}

\subsubsection{European Union}

Energy supply system in Europe is dominating by imported fossil fuels. To make energy supply more secure, the European Commission (EU) reduces the dependence on imported energy through reducing demand, diversifying the energy mix with usage of renewable energy, and diversifying sources and supply routes of imported energy.

The European Union (EU) began to set targets for renewable energies in 1997 in its White Paper on RES. An overall target of doubling the contribution from renewable energy in the final EU energy consumption from $6 \%$ to $12 \%$ by 2010 was set. Based on the RES White Paper, legislative frameworks have been put in place at EU level to ensure that overall targets will be achieved in the electricity and biofuel sectors. 
In the electricity sector, the EU placed its first legislative measure, a directive on the promotion of electricity from RES (Directive 2001/77/EC), to fulfill the targets. The directive defines national indicative targets for each Member State, encourages the use of support schemes, elimination of the administrative barriers and system integration. National indicative targets were set with the aim to raise the share of renewable electricity from $14 \%$ in 1997 to $22 \%$ in 2010 (revised to $21 \%$ after the number of Member States increased) [5].

In a longer term, the EU set a new target in 2008, aiming to increase the share of renewable energy in total energy consumption to $20 \%$ by 2020 . Each Member State is given a national target based on their existing renewable generation, GDP and a flat-rate increase for all. In terms of electricity consumption, it is estimated that at least $34 \%$ of total electricity generation will come from RES by 2020 [6].

\subsubsection{Germany}

The first main financial promotion and stimulation instrument for RES on the national level is Electricity Feed-in Law (StrEG) which was introduced in 1991. It requires transmission system operators (TSO) to accept electricity from RES into the grid and pay a feed-in price based on electricity retail price. In order to avoid an unfair burden cost on each TSO (there are 4 regional TSOs in Germany), a regional $5 \%$ cap was applied. Nevertheless, wind power generation systems installed under the StrEG are concentrated in Northern Germany, leading the grid operators in the North to complain about the higher prices for electricity.

The Renewable Energy Act (EEG) replaced the StrEG in 2000. Under the EEG, feed-in prices are set at a specific rate and fixed for 20 years. Furthermore, the regional caps were eliminated and the total amount of reimbursements is distributed evenly among all TSOs and their electricity consumers. The EEG was reviewed in 2002 and amended in August 2004. The amended Act includes a detailed target for renewable energy to comprise at least $12.5 \%$ of electricity production by 2010 and at least $20 \%$ by 2020 . Under the new law, the feed-in prices are reviewed every two years, considering technological and economic developments. The prices are also subject to an annual decrease depending on technology.

In 2009, Germany launched a revised Renewable Energy Act aiming to increase the share of RES in electricity supply to at least $30 \%$ by the year 2020 [7]. In the revised Act, adjustable degression rates of feed-in prices are applied to control the amount of new installation. For example, if the annual installation of PV exceeds $1700 \mathrm{MW}$ in 2010, the degression rate for 2011 will increase by $1 \%$ [8].

\subsubsection{Spain}

In 1997, Spain launched the Electric Power Act 54/1997 to set basic regulation to promote usage of renewable energies and co-generation (Special Regime). Based on Electric Power Act 54/1997, the "Renewable Energy Promotion Plan" was established, aiming to increase share of renewable energy in total energy demand to $12 \%$ by 2010 .

In 1998, Royal Decree 2818/1998 (RD 2818/1998) was launched and obligated the electricity distributor to accept the electricity from RES into the grid and pay a price which is derived from a fixed premium and spot price. However, due to the uncertainty of spot price, renewable energy growth was limited.

In 2004, Spain raised the renewable energy target to 20 GW by 2010 and launched Royal Decree 436/2004 (RD 436/2004) aiming to fulfill this target. Under RD 436/2004, alternative methodologies for selling power under the Special Regime were established. The owner of renewable generator can choose to sell their power under the following options: 
(1) Sell to the electricity distributor at the fixed price

(2) Sell to the market through the bidding system. The price is set by the market or negotiated by the parties in the case of bilateral contract, plus a premium.

The introduction of the market option within RD 436/2004 resulted in a strong increase of the electricity from RES, particularly wind power generation, as a consequence of rising electricity prices. As a result, cap and floor prices have been introduced under the Royal Decree 661/2007 (RD 661/2007). On the other hand, the incentives for PV and solar thermal power generation have been raised to accelerate usage of solar energy [9] [10].

However, due to high incentive level under RD 661/2007, the annual installation of large scale PV grew unexpectedly more than $2.4 \mathrm{GW}$ in 2008. As a result, Spanish government later launched Royal Decree 1578/2008 (RD 1578/2008) to set an annual installation cap [8].

\subsection{Current Status and Projection}

Europe continues to be one of the strongest regions for new development in wind power generation, with over $8.4 \mathrm{GW}$ of new installed capacity in 2008. For the PV power generation, Europe is leading the global market for PV applications since taking over the number one position from Japan in 2004. Among EU members, Germany has been leading the way for renewable energies for several years while Spain has been following closely. Germany and Spain are expected to remain the leading markets in Europe, but other countries such as Italy and France are growing strongly. Renewable energy is expected to provide about $35 \%$ of the EU's electricity by 2020 . Wind energy is set to contribute more than a third of all the power coming from RES [6].

Electricity generation by fuel in Germany is shown in Figure 5. About $68.2 \%$ of electricity in Germany is generated from coal and nuclear energy. Renewable energy represented about $11.6 \%$ in 2006 . However, because Germany will phase out nuclear power plants, renewable energy is expected to play an important role in reducing $\mathrm{CO}_{2}$. According to German Wind Energy Association (BWE), the overall German onshore capacity could be $45 \mathrm{GW}$, with an additional $10 \mathrm{GW}$ offshore by 2020 [2]. On the other hand, EPIA estimates that PV market in German could grow 4 GW annually by 2013 if the current financial support scheme is maintained [3]. For the longer term, according to system adequacy forecast (SAF) by European Network of Transmission System Operators for Electricity (ENTSO-E), the total installed capacity of wind and PV power generation could reach 53 GW and 17 GW in 2020 as shown in Figure 7 [11].

Most of the electricity in Spain is generated from natural gas, coal and nuclear energy as shown in Figure 6. Renewable energy, mainly from hydro and wind power, represented about $17.1 \%$ in 2006 . Wind power generation is expected to continue its steady growth. The Spanish Wind Energy Association (AEE) estimates that $40 \mathrm{GW}$ of onshore and $5 \mathrm{GW}$ of offshore wind capacity could be operating by 2020 [2]. On the other hand, PV market in Spain is expected to slow down due to the government's 500 MW annual installation gap (RD 1578/2008) from 2009 to 2011. EPIA estimates that the total installed capacity of PV in Spain could reach between 6 and 7 GW in 2013 [3]. For the longer term, total installed capacity of wind and PV power generation could rise to $14 \mathrm{GW}$ and $45 \mathrm{GW}$ by 2020 as shown in Figure 8 [11].

It should be noted that increasing the share of intermittent energy sources and decreasing the share of thermal power plants could result in difficulty of power balancing in both countries. 


\section{Figure 5}

Electricity Generation by Fuel in Germany (2006)

\section{Total Gross Generation 637 TWh}

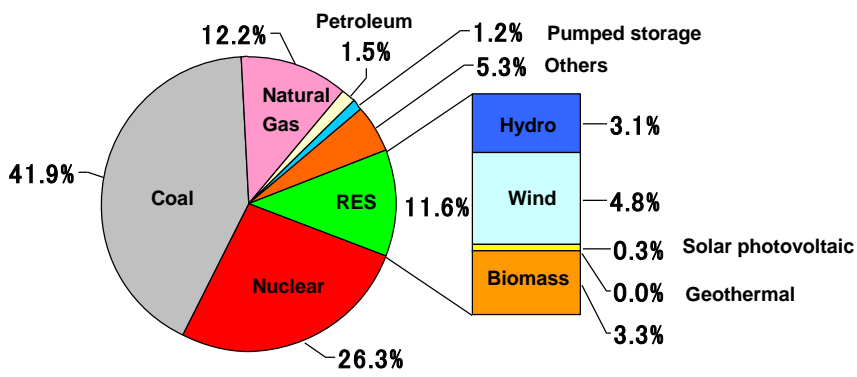

Source: EuroStat Energy Yearly Statistics 2006
Figure 6

Electricity Generation by Fuel in Spain (2006)
Total Gross Generation $=303 \mathrm{TWh}$

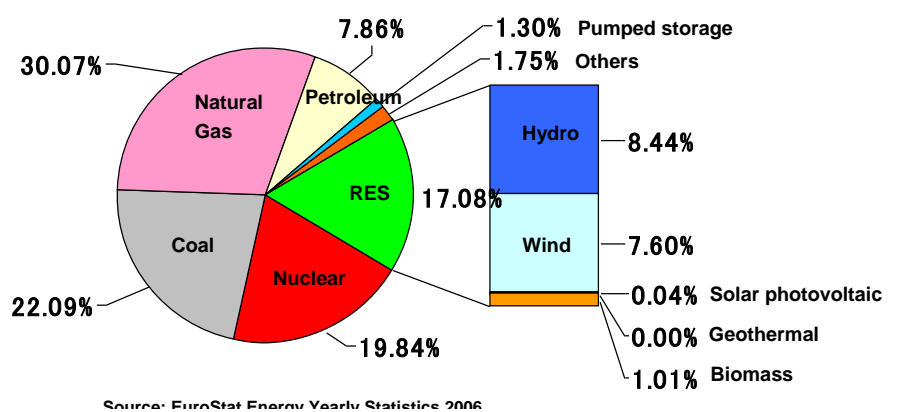

Figure 7

Projection of

Generation Mix in

Germany

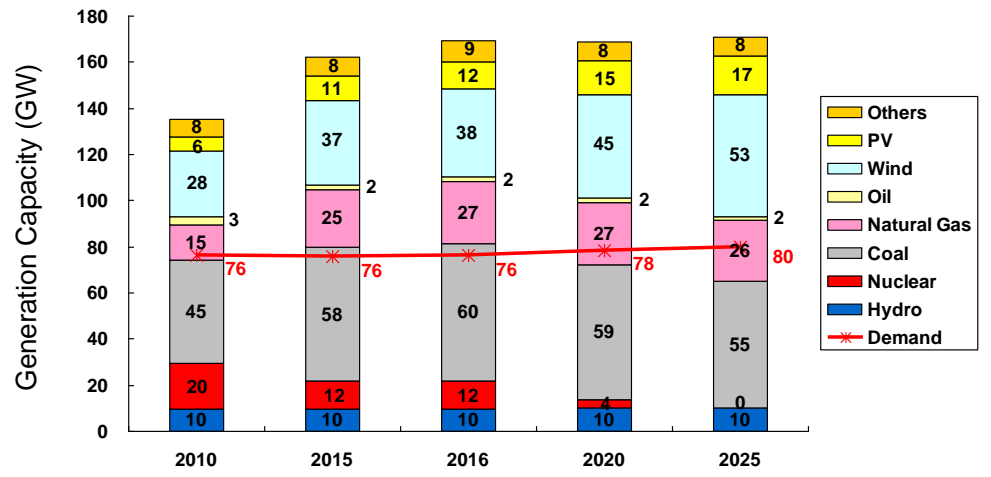

Source: European Network of Transmission System Operators for Electricity
Figure 8

Projection of

Generation Mix in

Spain

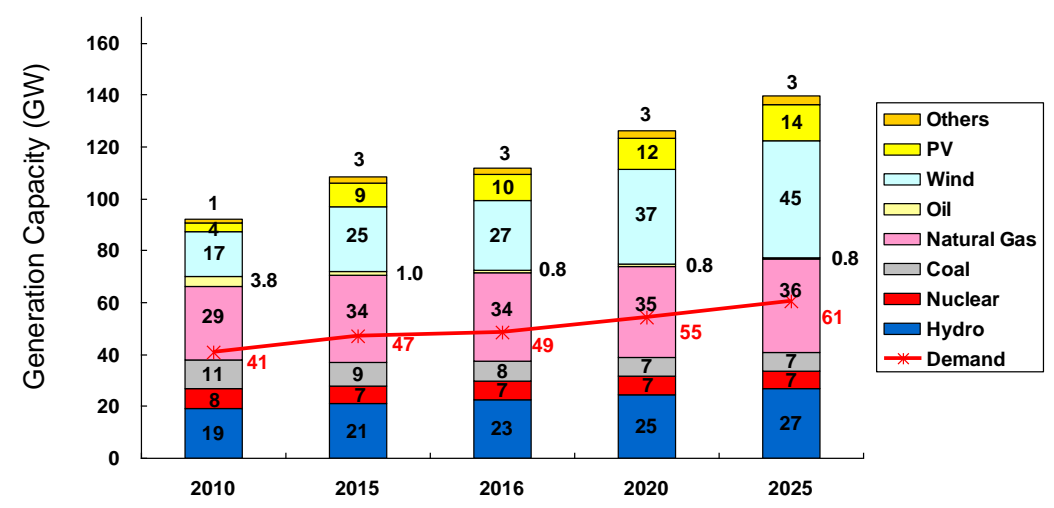

Source: European Network of Transmission System Operators for Electricity 


\section{Status of Renewable Energy in U.S.}

This section provides details for typesetting your manuscript according to the formatting guidelines set for ENGINEERING JOURNAL. Please use a 10 points Arial Regular for the typesetting of your whole document.

Note that, in ALL Sections or Subsection, there will be no indentation in every paragraph. Each paragraph should be with 10 points of white space both before and below the end of it.

\subsection{Policy Background}

In response to the oil crises, U.S. government passed the Public Utility Regulatory Policy Act (PURPA) in 1978 to reduce dependence on foreign oil and promote alternative energy sources and energy efficiency. PURPA required utilities to buy power from independent companies that could produce power for less than what it would have cost for the utility to generate the power, called the "avoided cost". Due to high price of oil, PURPA was the effective measure in promoting renewable energy during that period. However, after the price of oil declined, PURPA was eventually no longer useful tool to promote usage of renewable energies.

To overcome the drawback of PURPA and promote usage of renewable energy, Renewable Portfolio Standards (RPS), also known as a Renewable Electricity Standard (RES), have been introduced at the state level in the late 1990s. RPS requires electricity retailers to provide a minimum specified share of their total electricity sales from qualifying renewable power generation. Because of retailer is free to choose type of renewable energy, RPS benefits only the least-cost renewable energy technologies. As a result, an increasing number of states have begun to set their RPS policies to provide differential support to promising but currently higher-cost renewable technologies such as solar energy. Typically, this support has been provided either through credit multipliers, in which favored renewable technologies are given more credit towards meeting RPS requirements than other technologies, or through specific target, in which some fraction of the RPS must be met with favored technologies. Currently, RPS exists in 29 U.S. states and District of Columbia, but not at the national level [12]. One of the most aggressive state RPS requirements in the country is that of California, which requires that $33 \%$ of its electricity come from renewable energy by 2020 .

In the national level, Production Tax Credit (PTC) is the primary incentive for renewable energy. PTC is a per-kilowatt-hour tax credit for electricity generated by qualified energy resources and sold by the taxpayer. Since its establishment in 1992, the PTC has been renewed and expanded several times, most recently in 2009 which will be valid until the end of 2012. Another incentive at the federal level is the Investment Tax Credit (ITC). It went into effect in 2006, and has been periodically extended and amended. Current ITC, which is valid until the end of 2016, is a $30 \%$ tax credit for purchase and installation of residential and commercial renewable gridconnected systems.

The combination of federal tax incentives and state RPS requirements are the most important drivers of renewable generation installation in U.S.

\subsection{Current Status and Projection}

In the U.S., wind power generation is the fastest growing renewable electricity technology. Installed capacity increased almost 10 times between 2000 and 2008. In 2008, U.S. surpassed Germany as the world leader in wind power generation with the total installed capacity of $25 \mathrm{GW}$.

On the other hand, PV market increased $338 \mathrm{MW}$ in 2008. Of this market, 87\% (293 $\mathrm{MW}$ ) were grid-connected systems and $13 \%$ (45 MW) were off-grid installations. Total installed capacity reached $1.2 \mathrm{GW}$ by the end of 2008 [13]. It should be noted that offgrid installations in U.S. is high compared with other countries as shown in Table 1. This is because of PV is an economical option for resident in the remote area and applications such as telecommunication and pump, particularly less than $10 \mathrm{~kW}$ system. It costs about 20,000 to 80,000 dollar to extend a 1-mile long distribution line in the U.S. 


\begin{tabular}{|c|c|c|c|c|c|}
\hline \multirow{2}{*}{ Country } & \multicolumn{2}{|c|}{ Off-grid } & \multicolumn{2}{c|}{ Grid-connected } & \multirow{2}{*}{$\begin{array}{c}\text { Total Capacity } \\
\text { (MW) }\end{array}$} \\
\cline { 2 - 5 } & $\begin{array}{c}\text { Domestic } \\
\text { (MW) }\end{array}$ & $\begin{array}{c}\text { Non-domestic } \\
\text { (MW) }\end{array}$ & $\begin{array}{c}\text { Distributed } \\
\text { (MW) }\end{array}$ & $\begin{array}{c}\text { Centralized } \\
\text { (MW) }\end{array}$ & 2144 \\
\hline Japan & 2 & 89 & 2044 & 9 & 5340 \\
\hline Germany & \multicolumn{2}{|c|}{40} & \multicolumn{2}{|c|}{5300} & 3354 \\
\hline Spain & \multicolumn{2}{|c|}{31} & \multicolumn{2}{|c|}{3323} & 1169 \\
\hline U.S. & 154 & 216 & 735 & 65 & \\
\hline
\end{tabular}

Source:Trends in Photovoltaic Applications (IEA-PVPS T1-17:2008), Large-Scale Photovoltaic Power Plants Annual Report 2007and National Survey Report of PV Power Application in UK

Electricity generation by fuel in U.S. is shown in Figure 10. Electricity in U.S. is dominated by coal $(49 \%)$, natural gas $(20 \%)$ and nuclear (19\%). Renewable energy represents only $8.5 \%$ of electricity in 2006 . Among, the renewable energy, hydro has a highest share of $7 \%$.

Figure 11 shows projection through 2035. It is based on results from the Energy Information Administration's National Energy Modeling System, assuming that electricity consumption increases at an average annual rate of $1.0 \%$ [14]. It is forecasted that coal will remain the dominant energy source for electricity generation because of continued reliance on existing coal-fired plants. Natural gas will play a larger role because it is more attractive than coal in term of environmental impact, and because it is cheaper compared with renewable energy. Wind and PV power generation development in U.S. will see a small drop in the next few years as a result of economic meltdown. Nevertheless, it is expected that it will recover quickly in response to the extension of tax credits and other financial support programs. As for the wind power generation, it is pointed in the report from Department of Energy (DOE) that wind power has potential to provide $20 \%$ of U.S. electricity by 2030 [15].

\section{Total Gross Generation 4078 TWh}

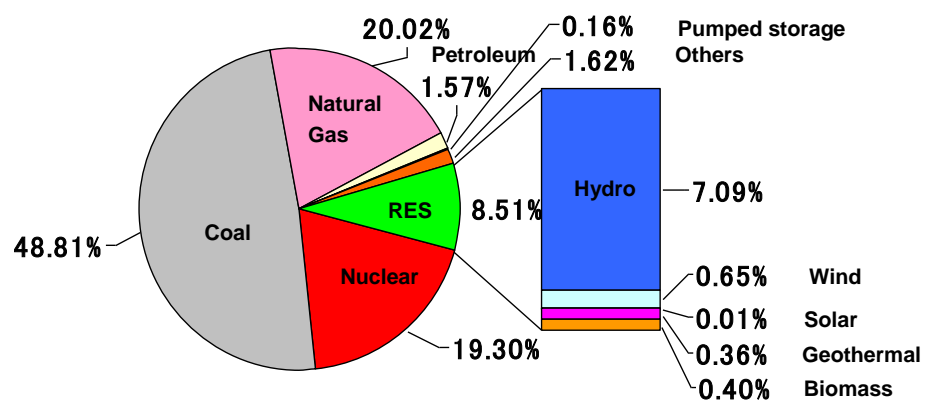

Source: DOE

Electricity Generation by Fuel in U.S. (2006)

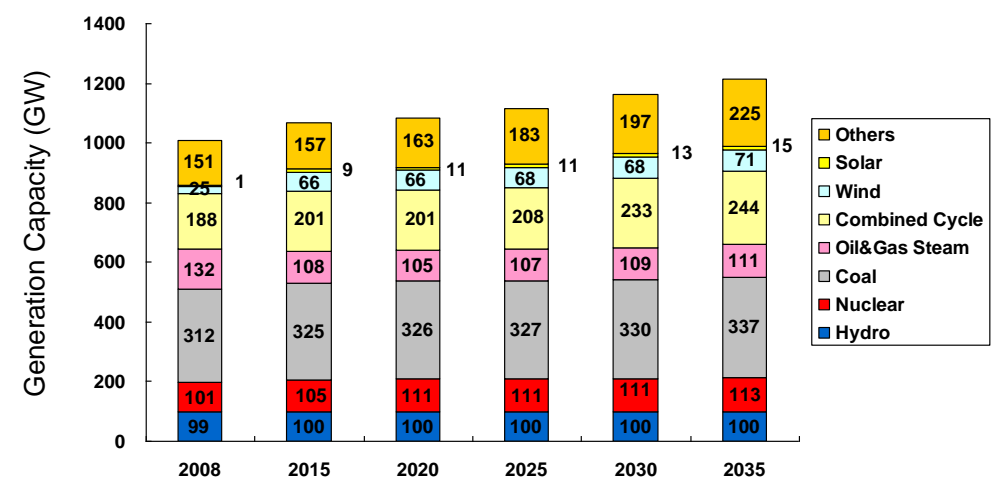

Source: U.S. Energy Information Administration 


\section{Status of Renewable Energy in Japan}

\subsection{Policy Background}

Japan is dependent on imports for $96 \%$ of its primary energy supply. Following the two oil crises in the 1970s, Japan has diversified its energy sources through increased use of alternative energy such as nuclear, natural gas, coal and renewable energy, as well as promotion of energy efficiency and conservation. As a result, share of oil among the primary energy supply has been significantly lowered to the current level, approximately $50 \%[16]$.

In 1997, Law Concerning Special Measures to Promote the Use of New Energy (New energy is defined as oil-alternative energy that is not sufficiently used for economical reasons) was enacted to declare the basic policies on new energy and accelerate the introduction of new energy through financial aids. Subsidies and tax incentives have been implemented by the Minister of Economy, Trade and Industry (METI). It should be noted that Japan is the first country to introduce subsides for the implementation of residential PV systems. As a result, Japan emerged as world leader in PV installation and production for over years, before replaced by Germany in 2005.

To ensure the stability and suitability of energy supply, the Special Measures Law Concerning the Use of New Energy by Electric Utilities (RPS Law) was launched in 2003 to further usage of new energy by annually imposing an obligation on electricity retailers to use a certain amount of electricity from new energy according to the amount of their retailing electricity.

In 2006, the METI drafted the New National Energy Strategy in response to concerns on energy security caused by rapid growth of energy demand in Asia, particularly in China and India. It presents long-term energy strategy focusing on the reinforcement of energy security and stipulates numerical targets. The important goal is to have the share of nuclear energy at the level at least $30 \%-40 \%$ by 2030 and thereafter. Regarding to new energy, the goal is to reduce to cost of new energy to the level of conventional thermal power plant by 2030 [17].

In 2008, the METI announced the Long-term Energy Supply and Demand Outlook and set numerical target for each technology. Based on this outlook, the former Prime Minister Yasuo Fukuda announced plan (called Fukuda Vision) to boost Japanese solar panel market by set a target to increase PV capacity to 14 GW and 53 GW by 2020 and 2030, respectively [18]. Hereafter, in 2009, the former Prime Minister Taro Aso increased 2020's PV installation target to $28 \mathrm{GW}$ in his "Future Development Strategy", aiming to be the number one solar power nation in the world again [19].

Place Tables/Figures/Images in text as close to the reference as possible. (see figure 1). The table, figure or image has to put in the area which is width $14.5 \mathrm{~cm}$., filled with $70 \%$ black color. You should leave $2 \mathrm{~mm}$. from margin. In a side box (width $3.8 \mathrm{~cm}$., filled with 15\% Black), a short caption could be in the bottom.

\subsection{Current Status and Projection}

Since laws and financial support programs from government were enacted, wind and PV power generation have been largely installed as shown in Figures 12 and 13. As of December 2008, the total installed capacity of wind and PV power generation reached $1.9 \mathrm{GW}$ and $2.1 \mathrm{GW}$ respectively. Compared with EU and U.S., the installed capacity of $\mathrm{PV}$ is higher than wind power generation because of the following reasons.

- The weather condition in Japan is not appropriate for wind power generation. One-third of the wind turbines have experienced malfunctions or failures due to natural phenomena such as typhoons and lightning.

- In consideration of the limited land space, rooftop PV system has higher potential for growth than wind and other renewable technologies.

- Japan has a lot of PV manufacturers. Enlarging PV market will boost Japanese economic. 


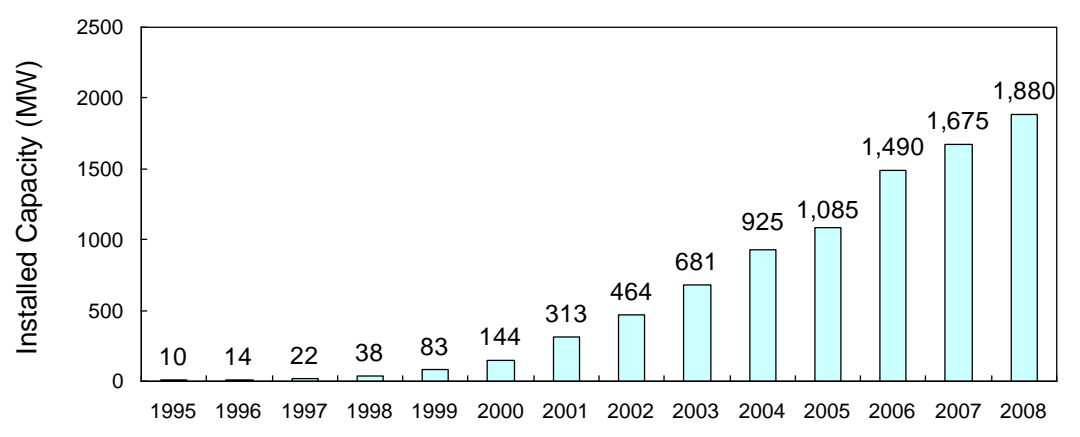

Source: New Energy and Industrial Technology Development Organization

Figure 12

Cumulative Installed

Capacity of Wind

Power Generation in

Japan

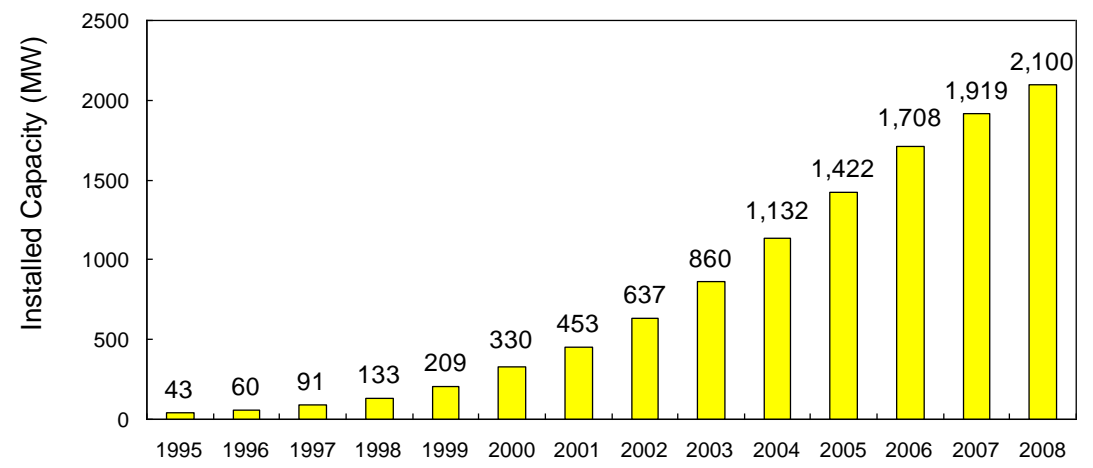

Source: National Survey Report of PV Power Application in Japan and Global Solar Report Card
Figure 13

Cumulative Installed Capacity of Photovoltaic Power Generation in Japan

On the long term, it is estimated that electricity demand will slow over the coming 30 years, due to declining population. It is forecasted that electricity demand will increase annually by $0.8 \%$ on average up to 2015 . Nuclear generation is the key base-load power source and will continue to play an important role in contributing to stable supply and deal with global environmental issues. High thermal efficiency Coal-fired and Liquefied natural gas (LNG) fired power generation are also expected to expand due to their economic performances.

Projections of (installed capacity and generated electricity) until 2030 are shown in Figures 14 and 15. The projections were determined considering 3 cases as follows:

Case 1: Reference: Assuming that present technologies (2005) are applied without using new technologies

Case 2: Continuation Effort: Assuming that technology (equipment efficiency) is extended based on the current development speed.

Case 3: Maximum Introduction: Assume that financial support from government as well as advance technologies, including technology for energy conservation, are applied.

It is expected that share of renewable energy in the primary energy will increase to $11.1 \%$ by 2030 , in the maximum introduction case. The installed capacity of wind and PV power generation would be $6 \mathrm{GW}$ and $53 \mathrm{GW}$, respectively.

However, it is pointed that the current Japanese power system might accept the interconnection of up to $5 \mathrm{GW}$ and $10 \mathrm{GW}$ of wind and PV power generations, respectively. Higher penetration of requires a major renovation of power system infrastructure and way of operation [4]. 
Figure 14

Projection of

Generation Mix (GW)

in Japan.

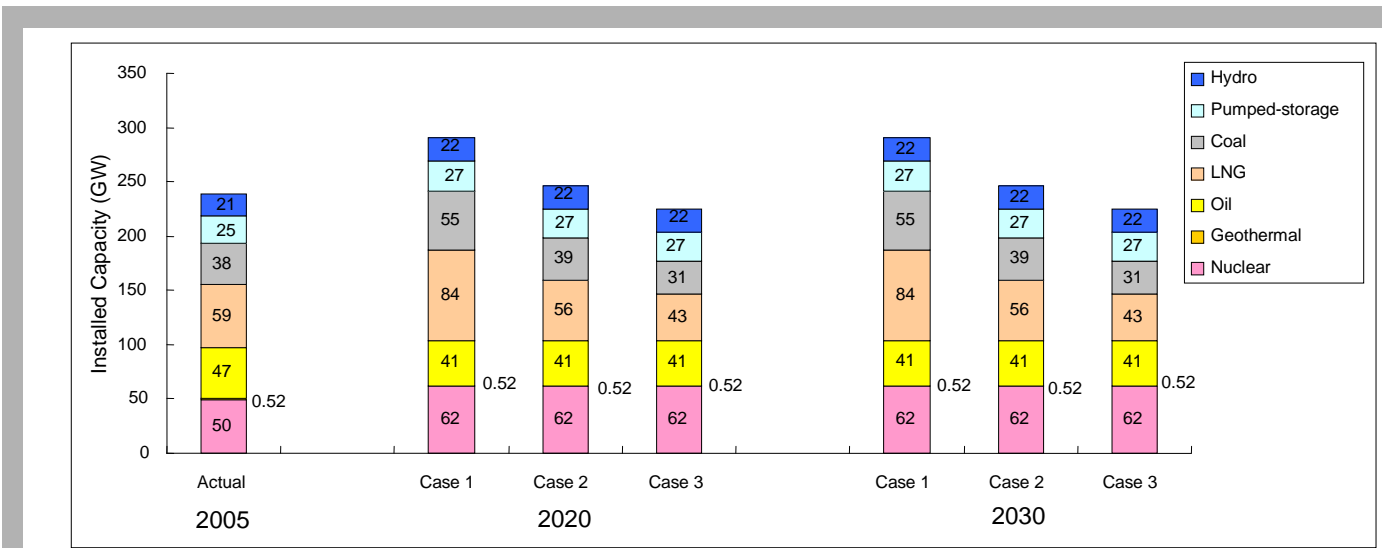

Source: Ministry of Economy, Trade and Industry
Figure 15

Projection of

Generation Mix

(GWh) in Japan.

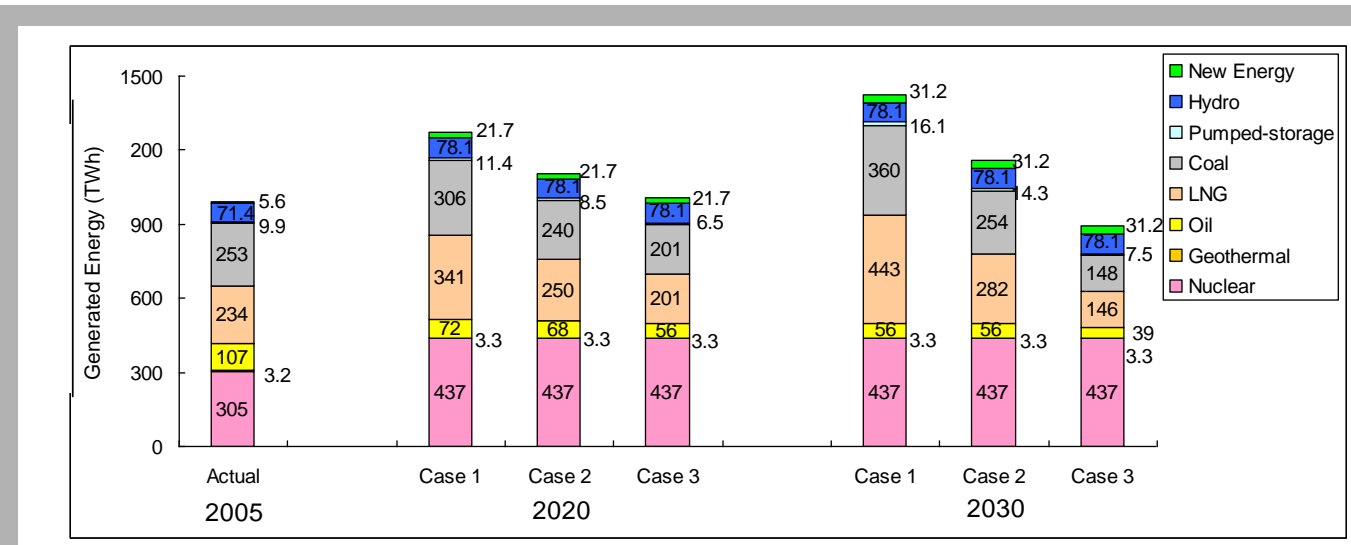

Source: Ministry of Economy, Trade and Industry

\section{Impact of Large Penetration of Wind and PV Power Generation on Power System Operation}

Although, wind and PV power generation contribute to $\mathrm{CO}_{2}$ reduction and energy security, their possible negative impacts on power system operation are widely concerned. Integration of large amount of wind and PV power generation into the electric power system presents challenges to power system planners and operators.

In this section, the possible impacts on power system, particularly from balancing, stability and reliability viewpoints are addressed

\subsection{Balancing}

Because wind and PV power generation outputs vary with location and weather, there is no guarantee that they will provide electricity when it is needed. As a result, an additional power reserve from other dispatchable generation sources is required to cover its sudden reduction.

In contrast, during the off-peak time, wind and PV power generation may generate electricity more than expected amount. Usage of pumped storage or battery is needed to absorb the extra generation. It becomes more difficult for a country like Japan, where the output of base-load power generation such as nuclear power plant is not changed in the normal operation.

When wind and PV power generation have reached significant penetration levels, capacity of backup generation or storage system might be insufficient or unable to compensate fluctuation on time. High accuracy forecasting tool and probabilistic based unit commitment/economic dispatch will play an important role. Moreover, limitation of output from wind and PV power generation might be needed. 


\subsection{Stability}

There are some types of wind and PV power generation which instantly disconnect when a voltage drop occurs. When wind and PV power generation have reached significant penetration levels, simultaneous disconnection could result in power system instability.

To overcome this problem, several countries have set grid code requiring wind power generation to keep online for a certain period of time in event of sudden voltage drop occurs due to disturbance in the network. This requirement is called Fault Ride Through (FRT) or Low Voltage Ride Through (LVRT). List and more detail of grid code can be found in [20] - [24].

In addition to FRT requirement, in Spain, Control Centre of Renewable Energies (CECRE) was established in 2006 to supervise and control of the renewable energy generators, mainly wind power generation, of over $10 \mathrm{MW}$. Though, real-time security assessment, a maximum power limit that each wind farm is permitted to produce is computed [25].

\subsection{Reliability}

In order to keep power system reliable, it must be ensured that more generation capacity is available than is necessary to serve electricity demand. Because wind and PV power generation outputs are uncertain, an additional power reserve from other dispatchable generation sources is required to cover a variation. However, it is costineffective to backup every MW from wind and PV power generation.

Although wind and PV power generation cannot be considered like other conventional power plants, where full capacity can be used in reliability evaluation, it is clear that their outputs are not simultaneously zero when a large amount of them are penetrated. Wind and PV power generation have some statistical capacity value (kW value) which can be relied on. Quantification of capacity value of wind and PV power generation is needed in the daily/weekly power plant schedule as well as long-term generation expansion planning.

The capacity value of wind and PV power generation depends on the weather condition and their correlations with the load. Generally, methodology to determined capacity value can be classified as follows:

- Effective load carrying capability (ELCC): The capacity value is determined based on power system reliability evaluation. Capacity value is the amount of load that can be increased after wind and PV power generation penetration, without losing reliability level (same Load of Load Probability or Load of Load Expectation).

- Peak Cut Contribution: The capacity value is determined from how much wind and PV power generation contribute to peak cut. For example, the average value of PV power generation during peak intervals.

- Capacity factor: The capacity value is simply determined from capacity factor of wind and PV power generation.

Detail of some methods to determine capacity value of wind and PV power generation can be found in [26] - [29].

\subsection{Other Issues}

In addition to balancing, stability and reliability, large penetration of wind and PV power generation could cause other problems. For example, wind and PV power generation fluctuation can lead to unpredictable variation of voltage and power flow. For wind and PV power generation that connected to distribution system, the voltage in distribution system sometimes becomes higher than the maximum nominal voltage because too much power injection from those generations.

Another issue is that most of RES, particularly wind power generation, is far away from load center. New transmission line is needed to transport electricity generated from those RES to the load center. For example, currently, 9 European countries (Belgium, 
Denmark, France, Germany, Ireland, Luxembourg, the Netherlands, Norway and the United Kingdom) are planning to build a power grid of high-voltage cables under the North Sea, which will transport energy generated by a mix of wind, solar, and tidal power to better balance supply and demand in Europe [30].

Some studies on integration of large penetration of wind power generation into power system can be found in [31], [32].

\section{Conclusions}

In this paper, current status and projection of renewable energy, particularly wind and PV power generation, in Europe, U.S. and Japan are summarized. As a countermeasure to reduce $\mathrm{CO}_{2}$ and secure energy, it is clear that the usage of renewable energy will increase drawing a concern on the possible impacts of wind and PV power generation to power system operation when its installed capacity reaches significant levels.

United State and several countries in Europe apply grid code to wind power generation in order to keep power system stable. In Spain, wind power generations are controlled online based on real time security assessment. On the other hand, from the reliability viewpoint, there are attempts to evaluate the capacity value of wind and PV power generation based on the locational weather condition and their correlations with the peak load.

To integrate large penetration of wind and PV power generation into electric power system, it is expected that technologies such as wind and PV power generation forecast and estimation will play an important role in the future.

\section{Biography}

Pathom Attaviriyanupap was born in Bangkok, Thailand, in 1976. He received the B.E. and M.E. degree from Chulalongkorn University, Bangkok, Thailand, in 1996 and 1998, respectively. In 1998, he was granted the Japanese MONBUSHO-Scholarship. Under this scholarship he completed research at Kyushu University, Fukuoka, Japan, in 2000 and received the Ph.D. degree from Hokkaido University, Sapporo, Japan in 2003. Between 2003 and 2005, he conducted research at The University of Tokyo, Tokyo, Japan under support from JSPS Postdoctoral Fellowships for Foreign Researcher. He was an Assistant Professor at Tokyo Institute of Technology, Tokyo, Japan between 2005 and 2008. Currently, he is with Mitsubishi Electric Corporation, Tokyo, Japan. His research interests are intelligent system application in power system, power system operation and planning, power system reliability and energy management 


\section{REFERENCES}

[1] Energy Information Administration, " The international energy outlook 2009," Annual Energy Outlook 2009, Washington, DC: 2009. [Online]. Available: www. Eia.doe.gov/oiaf/aeo.

[2] Global Wind Energy Council,“ Global wind 2008 report,” 2008.[Online].Available: http://www. gwec.net/index.php?id=92

[3] European Photovoltaic Industry Association, " Global market outlook for photovoltaic until 2013," [Online].Available: http://www.epia.org/home.html

[4] Press Conference by Chairman of The Federation of Electric Power Companies of Japan, May 2008. [Online].Available: http://www.fepc.or.jp/english/news/conference/_icsFiles/afieldfile/2008/08/27/200805_s1.pdf

[5] The European Parliament and and The Councilof the European Union, " Directive 2001/77/EC of the European parliament and of the council of 27 September 2001 on the promotion of electricity produced from renewable energy sources in the internal electricity Market," Official Journal of the European Communities, pp. 33-40, 2001.

[6] European Renewable Energy Council, " Renewable energy technology roadmap 20\% by 2020," [Online].Available: http://www.erec.org

[7] Act - Revising the Legislation on Renewable Energy Sources in the Electricity Sector and Ameding Related Provisions of 2008 [Online].Available:http://www.erneuerbare- energien.de/files/pdfs/allgemein/application/pdf/eeg_2009_en.pdf

[8] A. Kravetz, " 2008 Global solar report cards," Green Cross International. [Online].Available: http://www.globalgreen.org/docs/publication-96-1.pdf

[9] M. Ragwitz, and C. Huber, "Feed-in systems in germany and spain and a comparison," Fraunhofer Institute Systems and Innovation Research and Energy Economics Group, pp. 1-27, 2004.

[10] A. Held, M. Ragwitz, C. Huber, G. Resch, T. Faber, and K. Vertin, " Feed-in systems in germany, spain and slovenia - A comparison," Fraunhofer Institute Systems and Innovation Research and Energy Economics Group, pp. 1-37, 2007.

[11] "ENTSO-E report - System adequacy forecast (SAF) 2010-2025," European Network of Transmission System Operators for Electricity, pp. 1-112, [Online].Available: http://www.europolitics.info/pdf/gratuit_en/265762-en.pdf

[12] The Database of State Incentives for Renewable Energy (DSIRE) Homepage [Ōnline].Available: http://www.dsireusa.org/

[13] "Trends in photovoltaic applications - Survey report of selected IEA countries between 1992and 2008," International Energy Agency - Photovoltaic Power Systems Programme, pp. 1-40, 2009.

[14] "Annual energy outlook 2010 - Reference case," U.S. Energy Information Administration, Washington, DC: 2010. [Online].Available: www.eia.doe.gov/oiaf/aeo/

[15] American Wind Energy Association, 20 \% Wind Energy By 2030, [Online].Available: http://www.20percentwind.org/

[16] "Electricity review Japan," The Federation of Electricity Power Companies of Japan, 2007.

[17] "New national energy strategy (Digest)," Ministry of Economy, Trade and Industry, Japan, May. 2006.

[18] "Long-term energy supply and demand outlook," Ministry of Economy, Trade and Industry, Japan, May. 2008.

[19] Prime Minister of Japan and His Cabinet Homepage ," Speeches and statements by prime Minister," [Online].Available: http://www.kantei.go.jp/foreign/index-e.html

[20] The European Wind Energy Association, "Large scale integration of wind energy in the european power supply: analysis, issues and recommendations," The European Wind Energy Association, pp. 1-170, 2005.

[21] Transmission Code 2007," Network and system rues of the german transmission system operators," Verband der Netzbetreiber, 2007

[22] "Wind turbines connected to grids with voltages above $100 \mathrm{~kW}$," Elkraft System and Eltra, 2004. [Online]. Available: http://www.wt-certification.dk/Common/WindTurbinesConnectedtoGridswithVoltageabove100kV.pdf

[23] "Wind turbines connected to grids with voltages below $100 \mathrm{~kW}, "$ Elkraft System and Eltra, 2004. [Online]. Available : http://www.wt-certification.dk/Common/Regulation\%20for\%20Windturbines\%20TF\%203.2.6.pdf

[24] EirGrid, "EirGrid grid cose version 3.1," EirGrid,Technology Representative Inc., 2008.

[25] Control Centre of Renewable Energies Introductory Brochure, RED Electrica, 2009. [Online]. Available : http://www.ree.es/ingles/operacion/pdf/cecre/FolletoCecre_v4_ingles.pdf

[26] M. Milligan and K. Porter, "Determining the capacity value of wind: A survey of method and implementation," National Renewable Energy Laboratory, pp. 1-27, 2005.

[27] R. Perez, R. Margolis, M. Kmiecik, M. Schwab, and M. Perez, "Update: effective load-carrying capacity of photovoltaics in the United States," National Renewable Energy Laboratory, pp. 1-6, 2006.

[28] R. Perez, T. Hoff, M. Taylor, and J. P. Ross, "Photovoltaic capacity workshop: Developing consensus on a capacity methodology for PV generation," Solar Power, 2007.

[29] Xcel Energy," An effective load carrying capacity study for estimating the capacity value of wind generation resource - Final report," Public Service Company of Colorado, pp. 1-13, 2007.

[30] J. Blau, "Europe plans a North Sea grid," IEEE Spectrum, vol. 47, no, 3, pp. 12-13, 2010.

[31] IEEE Power and Energy Magazine, "Working with wind - Integrating wind into the power system," vol. 3, no. 6, Nov/Dec, pp. 88-90, 2005.

[32] R. Zavadil, N. Miller, A. Ellis, E. Muljadi, E. Camm, and B. Kirby, " Queuing up-interconnecting wind generation into the power system," IEEE Power \& Energy Magazine, vol. 5, no. 6, Nov/Dec pp. 47-58, 2007. 